\title{
INTERNATIONAL BOUNDARY EXPERIENCES BY THE UNITED NATIONS
}

\author{
Ayako Kagawa \\ Cartographic Section, Department of Field Support (DFS), United Nations, New York, 10017, USA - kagawa@un.org
}

KEY WORDS: Boundary, United Nations Cartographic Section, international boundary issues, Geospatial technology application

\begin{abstract}
:
Over the last few decades, the United Nations (UN) has been approached by Security Council and Member States on international boundary issues. The United Nations regards the adequate delimitation and demarcation of international boundaries as a very important element for the maintenance of peace and security in fragile post-conflict situations, establishment of friendly relationships and cross-border cooperation between States. This paper will present the main principles and framework the United Nations applies to support the process of international boundary delimitation and demarcation activities. The United Nations is involved in international boundary issues following the principle of impartiality and neutrality and its role as mediator. Since international boundary issues are multi-faceted, a range of expertise is required and the United Nations Secretariat is in a good position to provide diverse expertise within the multiple departments. Expertise in different departments ranging from legal, political, technical, administrative and logistical are mobilised in different ways to provide support to Member States depending on their specific needs.

This presentation aims to highlight some of the international boundary projects that the United Nations Cartographic Section has been involved in order to provide the technical support to different boundary requirements as each international boundary issue requires specific focus and attention whether it be in preparation, delimitation, demarcation or management. Increasingly, the United Nations is leveraging geospatial technology to facilitate boundary delimitation and demarcation process between Member States. Through the presentation of the various case studies ranging from Iraq - Kuwait, Israel - Lebanon (Blue Line), Eritrea - Ethiopia, Cyprus (Green Line), Cameroon - Nigeria, Sudan - South Sudan, it will illustrate how geospatial technology is increasingly used to carry out the support. In having applied a range of geospatial solutions, some of the good practices that have been applied in preceding projects, but there have been challenges and limitations faced. However, these challenges need to be seen as an opportunity to improve the geospatial technology solutions in future international boundary projects. This presentation will also share the aspirations that the United Nations Cartographic Section has in becoming a facilitator in geospatial technical aspects related to international boundary issues as we increasingly develop our geospatial institutional knowledge base and expertise. The presentation will conclude by emphasizing the need for more collaboration between different actors dealing with geospatial technology on borderland issues in order to meet the main goal of the United Nations - to live and work together as "We the Peoples of the United Nations".
\end{abstract}

\section{INTRODUCTION PRINCIPLES AND FRAMEWORK OF SUPPORT BY THE UNITED NATIONS}

Over the past decade, the United Nations has been approached by Member States to deal with international boundary delimitation and demarcation in many instances. The United Nations regards the process of the adequate delimitation and demarcation of the international boundaries as a very important element for conflict prevention between Member States. It is also a crucial baseline for maintaining the peace and security in a fragile post-conflict situation and establishing friendly relationships and cross-border cooperation.

States make profound efforts to demarcate their borders or resolving boundary related disputes with their neighbours. However, in many places, boundaries are still not yet delimited or demarcated with necessary precision.

Sometimes, neighbouring States have a history of mistrust, and in order to resolve their boundary dispute, they may invite mediation of a third party or rely on the arbitration decisions of courts ${ }^{1}$. It is in this context that the United Nations Secretariat may be invited by the parties concerned to participate in the mediation process.

\footnotetext{
${ }^{1}$ Whilst the International Court of Justice (ICJ) is a principal organ of the United Nations, it is an independent court that provides pacific settlement of international disputes; in this paper, reference to the United Nations will be specific to the United Nations Secretariat.
}

It is very important to emphasize that the expertise provided by the United Nations Secretariat is impartial and neutral by nature. The role of the United Nations in mediating boundary disputes is flexible with full involvement of the parties concerned. It is essential to stress that it is the Member States who take the lead in deciding border demarcation whilst the United Nations provides impartial and neutral expertise. United Nations involvement allows compromises based on negotiation during the different procedural phases leading to a more satisfactory result for all parties in comparison with arbitration court decision which does not allow parties concerned with room for negotiation or reconciliation. Furthermore, some Nations may not have sufficient expertise and capacity (political, mediation, legal, technical, logistics and administration) to proceed on their own and in this regard, expertise and capacity in dealing with international boundary mediation are available in the United Nations Secretariat.

Establishment of the Boundary Demarcation Commission is a prerogative of the Nations involved. The configuration and composition of the boundary demarcation commissions, and the decision-making bodies varies on a case-by-case basis. The senior United Nations management may be involved in the process and the representative of the UN Secretary-General may be part of the Commission. The role of United Nations Secretariat is to serve as a facilitator or implementer depending on the requests from the parties. 


\section{5 - 6 December 2013, Beijing, China}

Under the overall guidance of the Secretary-General, in cooperation with Department of Political Affairs (DPA), Department of Peacekeeping Operations (DPKO), Office of Legal Affairs (OLA), the United Nations Cartographic Section delivers necessary expertise in political, mediation, legal, technical, logistical and administrative matters in the demarcation processes. The UN Cartographic Section provides technical expertise as well as logistical and administrative support.

The United Nations Secretariat participates in different capacities depending on the level of United Nations involvement in the boundary demarcation process. If the United Nations provides the parties full scale support as a project manager, the United Nations Secretariat will cover all necessary aspects of the preparatory work as follows:

- Institutional organization: establishing together with the Parties the Boundary Demarcation Commission, organizing the Secretariat of the Commission, organizing the field demarcation team, establishing chain of communication of the Commission with respective provinces and local governments, directing the field work, etc.;

- Legal and administration: obtaining the necessary authorisation for decision-making by the Boundary Demarcation Commission, establishing of the procedures for making the decisions by the Commission, creating Terms of Reference for the field demarcation team, setting parameters of the physical representation of the boundary on land and water, developing special agreements and legal procedures, etc.;

- Technical support: analysis of existing legal and cartographic material, preparation of base map for demarcation and other necessary maps, organization and implementation of field survey, etc. The United Nations Secretariat also provides support in logistics, safety and security in the field operations on a need basis.

\section{BOUNDARY MAKING FRAMEWORK}

In general, boundary demarcation or boundary-making cycle can be divided into three phases: Preparation, Delimitation and Demarcation. After the completion of boundary demarcation, the fourth phase is management of the boundary.

\subsection{Preparation}

In the past, the United Nations has been involved with the demarcation of boundaries after a conflict. For example, in the cases of Iraq-Kuwait, Israel-Lebanon (Blue Line), EritreaEthiopia, the United Nations provided full scale support in the boundary demarcation. The United Nations also provides support to the Member States on their demand for boundary demarcation based on bilateral agreement as is the case for Cameroon-Nigeria, and North-South Sudan.

All the decisions on boundary demarcation will be made by the Boundary Demarcation Commission within the authority given by the governments; and the United Nations, if represented in the Commission, plays the role of facilitator.

The United Nations experts in legal, political and cartographic offices analyse different historical documents including maps, for interpretation, and transform the treaty text or coordinate information into geographic context, prepare reports and maps to present it to the Commission for their consideration.

In analysing different boundary-related material, it is very important to present the information and data graphically. This is usually done in the form of a base map for demarcation. The base map is used by the Commission with technical support of the UN experts for decision on delimitation of the boundary, detailed delineation of the boundary line in their demarcation decision and subsequently to serve as a treaty map.

\subsection{Boundary Delimitation and Demarcation}

The Secretariat of the Commission with the United Nations staff, supports the Commission in decision-making of the boundary demarcation parameters, facilitates field work on boundary survey and emplacement of the boundary pillars. In order to proceed with this job, the Secretariat administers necessary contracts, hires contractors and consultants (if needed) and purchases equipment to carry out the work. During the field operations, the Secretariat monitors and evaluates the demarcation process, facilitates all logistics and organizes the safety and security procedures.

The Secretariat provides technical assistance in support of decision making in the demarcation process such as extracting of boundary line from terrain analysis of digital elevation and satellite imagery in particular for inaccessible areas in order to reduce cost and/or expedite the decision of pillar location.

The Secretariat also prepares the draft report of the Commission on all aspects of the boundary demarcation and supports the Commission work on the preparation of the text of the boundary treaty, which could contain special agreements on the border trans-passing, use of the rivers and sea navigations.

The above-mentioned level of United Nations support was employed in the demarcation of the following boundaries: IraqKuwait, Israel-Lebanon (Blue Line) and Eritrea-Ethiopia. Partial technical and logistical support has been delivered to the following Nations based on their request during demarcation of the boundaries: Cameroon-Nigeria and North-South Sudan.

\subsection{Boundary management}

Boundary management is an important process which starts after the conclusion of the boundary demarcation and consists of: establishing of a bilateral committee (or commission) for boundary issues, protection of the border area and boundary line, maintenance of the boundary markers and associated boundary facilities, and establishing the procedures for border protection and cross-border cooperation.

Normally, States proceed with boundary maintenance on a bilateral basis, however in post-conflict situations, the United Nations may be asked to assume this task. For example, the United Nations provided maintenance for Iraq-Kuwait boundary and has since successfully transferred this responsibility to the Nations. To-date, the United Nations proceeds with the inspection and maintenance of the boundary markers and in the case of Israel-Lebanon with border protection.

The goal of the boundary management is to maintain and protect the border and to establish conditions for sustainable peace and security and cross-border cooperation between States.

\section{GEOSPATIAL TECHNOLOGY APPLICATION IN INTERNATIONAL BOUNDARY MAKING}

With the dynamic development of geospatial technology, boundary practitioners are increasingly leveraging this technology to be applied on the ground. This section will highlight some of the geospatial applications used in some of the international boundary projects that the United Nations Cartographic Section has been involved in the past decade. 


\section{5 - 6 December 2013, Beijing, China}

The international boundary between Cameroon and Nigeria was decided following the ruling of the International Court of Justice (ICJ) on the land and maritime boundary in October 2002. The land boundary has a length of approximately 1,690 kilometres with mixture of elevation and vegetation which poses challenges for the Cameroon Nigeria Mixed Commission (CNMC) established to demarcate it. In order to provide a practical solution for demarcation in accessible areas, the United Nations Office for West Africa (UNOWA) and the United Nations Cartographic Section have been providing technical support to CNMC through geospatial solutions to enable boundary demarcation and mapping in a more effective manner.

A watershed analysis workshop was organised by UNOWA and United Nations Cartographic Section for CNMC in August 2011. The objective was to develop an "In Office Method" $(\mathrm{OM})$ for areas which are inaccessible by the CNMC survey teams, allowing them to use the information using geospatial technology as a basis of delimitation agreement. Spot and Landsat Satellite imageries and 30 metres Digital Elevation Model (DEM) of the area were used to carry out watershed analysis whereby ridge lines were extracted to generate the main watershed line. Furthermore, a 3D visualisation technique was applied to illustrate how the ridge line would look like from different angles and positions. This allowed the CNMC members to negotiate and agree on the more precise location of the boundary line using geospatial technology.

This OM methodology allowed the CNMC to agree on demarcation of 118 kilometres out of the 1,800 kilometres along the entire boundary. In turn, this enabled the CNMC to continue its demarcation agreements from a technical perspective at a faster speed. In June 2013, the United Nations Cartographic Section hosted a Working Session together with UNOWA to CNMC to assist in their negotiation and agreement on the development of map templates which would be the basis for their final treaty maps production once the full demarcation has taken place.

The independence of South Sudan on 9 July 2011 following a referendum meant that the international boundary between Sudan and South Sudan has come into effect despite the reality of some areas have not yet been finalised in its negotiation of determination of allocation. The United Nations has been involved in providing technical assistance to the Technical Border Committee of North and South Sudan following the Comprehensive Peace Agreement in 2005.

Since September 2007, the experts of United Nations Cartographic Section participated in boundary workshops for the Technical Border Committee. Both in June 2009 and February 2010, the United Nations Mission in Sudan (UNMIS) and United Nations Cartographic Section provided technical workshops to the Technical Border Committee of North and South Sudan in order to facilitate their negotiations with regards to their boundary delineation and demarcation. Substantive technical assistance on utilising satellite imagery and base maps over the border areas was also provided to the Committee. Furthermore, in April and May 2009, UNMIS provided technical training on GIS and Remote Sensing to the committee members. SPOT satellite image maps along their entire boundary length of approximately 2,000 kilometres at a scale of $1: 100,000$ were produced and provided to the Border Committee, as part of a supporting tool for the negotiations.

To-date, there are few remaining areas which Sudan and South Sudan are still negotiating through mediation by the African Union (AU). The UN Cartographic Section has provided technical advisory and support to AU as they have established a programme known as the African Union Border Programme
(AUBP) to build its capacity to provide boundary related mediation services to African nations.

A project that the UN Cartographic Section is currently involved and finalising is the Iraq Kuwait Boundary Maintenance Project (IKBMP). The boundary length between Iraq and Kuwait is approximately 200 kilometres was demarcated following the UN Security Council Resolution 833 in 1993 but its maintenance was left under the responsibility of the United Nations since then. Due to the fragile political and security situation in the region, the boundary maintenance project was initiated in 2005 but only was reactivated in May 2012 and implemented in 2013. A United Nations team was sent along the boundary for field maintenance between January and March 2013 where they conducted substantive repair work of boundary installation (boundary pillars, witness marks, pointer marks, etc.). With the completion of the boundary maintenance on the ground, the two Nations agreed to sign a Memorandum of Understanding to establish a Joint Border Committee to assume its joint responsibility in maintaining the border in the future bilaterally in May 2013. This development can be seen as an evidence of confidence building and restoration of trust by the Member States.

\section{BUILDING BOUNDARY EXPERTISE AND CAPACITY}

In order to be better prepared, the United Nations Cartographic Section has been striving to build its internal institutional knowledge with regards to international boundary issues. As a technical office responsible for base maps for the United Nations Secretariat, the Section has been providing technical guidance and sharing of information and data related to international boundary within the United Nations Systems.

The United Nations Cartographic Section has therefore been developing an institutional knowledge base known as United Nations International Boundary Information System (UNIBIS) whereby authoritative information related to boundary are collected and translated into a geospatial context.

Authoritative information such as treaty text, treaty coordinates, treaty maps are collected and processed into a Geographic Information System (GIS) database using reference geospatial data and information such as satellite imagery as a backdrop. Following the collection of the information, the data is generalised and harmonised at 1:1,000,000 against the global dataset. This allows the United Nations community to use this information as a basis for their thematic mapping and analysis based on their operational requirements.

One of the greatest institutional challenges is the availability of resource as the importance of geospatial information is only highlighted when a conflict arises and not necessarily in the preparation and prevention phase where conflict may not be in the radar for decision makers. However, the Section believes that preparedness is the key to prevention of conflicts as the clear delineation and demarcation of sovereignty is an interest to all Nations.

\section{BORDERS LESSONS LEARNED}

The United Nations Cartographic Section's experience in international boundary making suggests that the best result could be achieved if the delimitation of the boundary and its demarcation followed the process of negotiation between the neighbouring Nations with or without the involvement of the third parties. If difficulties arise amongst the parties in some aspects of the boundary negotiation, the United Nations is willing to provide necessary support in technical, legal, 
political, logistics, etc. in order to obtain the success required in the boundary delimitation and demarcation. The United Nations Secretariat has the capacity to support the efforts of the Member States on boundary demarcation and has built experiences in organizing full scale boundary demarcation project.

In all stages of the life cycle of boundary making, it is very important to prepare an agreed base map along the common boundaries. This is a fundamental base product for preparation, delimitation, demarcation and management of the boundary as well as cross-border cooperation, etc. Our experience suggests that the most suitable map is an image map made from fresh satellite imagery or aerial photographs employing a suitable reference datum and topographic projection. To improve accuracy, a local datum could be used or established if appropriate local datum is unavailable. Scale of the base map could vary depending on the complexity of the terrain and objectives of its use from 1:2,500 to 1:100,000.

Another of the lessons learned is that the employment of latest geospatial technologies allows full advantage in boundary demarcation process particularly in not only enhancing for decision making through impartial scientific solutions but also avoids debates on impractical proposals based on reality on ground. These technologies such as geographic information systems (GIS), remote sensing, satellite imagery, terrain analysis, 3D fly through, global positioning system (GPS) should be continued to be applied in the context of international boundary issues. The more comprehensive and practical applications are implemented on the ground, the more high resolutions the imagery are or accurate digital elevation models are derived, the more the leaders of the different States will be convinced that this is a useful decision making tool to enhance the process of international boundary demarcation and building efficient and effective cross-border cooperation mechanisms.

The United Nations therefore continues to welcome the collaboration between different actors dealing with geospatial technology to contribute further in this process. One platform is the United Nations Initiative on Global Geospatial Information Management (UN-GGIM) where it aims at setting the agenda for the development of global geospatial information and to promote its use to address key global challenges. The United Nations welcomes the request for further support in demarcation and delimitation exercises around the world, especially in those regions where capacity and resources may be limited. However, it is important to note that the United Nations is only able to be involved if we are asked by the Member States concerned or in case of conflicts, by the decision of the United Nations Security Council or United Nations General Assembly. 